\title{
Neural substrates of cognitive bias and anxiogenesis
}

\author{
Arun L. Jadhav \\ Department of Biopharmaceutical Sciences, Roosevelt University College of Pharmacy, USA
}

\begin{abstract}
This review is designed to provide a brief overview of biology of stress-induced neurocognitive processing and mechanisms that contribute to susceptibility (reactivity) and resistance (resiliency) to anxiogenic disorders and examine a potential for developing experimental paradigm better suited for identifying new treatment targets.
\end{abstract}

\section{Introduction}

Processing of stressful stimuli and periodically feeling somewhat anxious is an aspect of animal and human development [1], however the increasing global prevalence of anxiety disorders is compelling investigations focused primarily on when and how these feelings become clinically significant disorders. The abundance of published scientific literature indicates the efforts devoted to understand the biology of neurocognitive processing of stressful stimuli and the pathophysiology associated with these processes. Although these efforts have produced therapeutically useful pharmacologic treatment strategies, the abuse potential and side effects of these agents, their limited usefulness in pediatric and elderly population, and women [2] combined with increasing global burden of anxiety-related disorders [3,4] is driving the search for better treatment strategies fort these disorders. Varying definitions and techniques of inducing stress, difficulties in connecting animal and human behavior to specific neuronal pathway and the nature of evolving diagnostic criteria present additional challenges. Use of clearly defined criteria for testing and characterizing anxiety and depression-related behaviors in animal models have also been proposed [5].

Anxiety has been described as an innate behavioral response necessary for survival and adaptation to the environment and clinicians define it as "a subjective sense of unease, dread, or foreboding, and can indicate a primary psychiatric condition or its component" [6]. Disorders with pathologies that include anxiety-related debilitating psychological and physiologic responses are widespread in the U.S. and according to one report about $18 \%$ of adults may seek treatment for anxiety disorder [7]. A recent study analyzed global burden and regional occurrence of anxiety disorders and estimated that the prevalence of anxiety disorders was $7.3 \%$ and ranged from $5.3 \%$ in African cultures to $10.4 \%$ in Euro/Anglo cultures [3,4]. Continuous presence of images of natural and man-made disasters including presence of terrorist atrocities on widely circulated digital media has added to the sources of potentially anxiogenic stimuli and it has been suggested that global burden of anxiety disorders will increase significantly $[1,8]$.

Thus, biology of effects of stress has been a focus of several studies and it has been fairly well established that distinct brain regions are involved in processing stress stimuli and generating adaptive responses as a part of animal and human survival, and that defects in these processes can lead to anxiety disorders [9-11]. However, a conundrum in these efforts is that while much of the research in animal models has focused on adaptive responses to threat stimuli that activate mechanisms in acquisition and extinction of fear [12-14], human anxiety disorders are related to defects in processing less ambiguous stimuli associated with uncertainty of threat [13-17] and cognitive bias is a key component of the pathogenesis of human anxiety disorders [1]. Thus, while significant progress has been made towards understanding the biological processes in fear conditioning and extinction, biological basis of neurocognitive processing of ambiguous worry some stimuli related to human anxiety disorders is not as clearly understood.

\section{Cognitive processing of stressful sensory input}

Mechanisms involved in processing information regarding stress/ threat have been reviewed extensively [1,18-20]. A conceptual overview of the cognitive processing of stress stimuli in anxiety disorders is depicted in Figure 1. It has been proposed that negative cognitive biases play a central role in the onset and maintenance of anxiety and depression [21-25]. The downstream effects of these biases such as negative self-evaluation, heightened arousal, and increased anxiety have also been demonstrated [26,27]. A cognitive processing model of fear and anxiety, linking distinct brain structures to specific stages of information processing of perceived threat has also been proposed [28]. These studies have led to the proposition that the human anxiety disorders can be divided in two categories: Those characterized by an underactivity of the prefrontal cortex, disinhibition of amygdala and intense fear and panic (Panic disorder, post-traumatic stress disorder, and phobias); and disorders that involve worry and rumination are characterized by an over activity of the prefrontal cortex (Generalized Anxiety Disorder and Obsessive-Compulsive Disorder) [29].

\section{Amygdala reactivity and anxiety disorders}

Many studies have established that early life experiences affect the manner in which amygdala reacts to stress later in life. A long-

Correspondence to: Arun L. Jadhav, Ph.D., Professor of Pharmacology, Department of Biopharmaceutical Sciences, Roosevelt University College of Pharmacy 1400 N. Roosevelt Rd. Schaumburg, IL 60173, USA; Tel: 847-3304549; E-mail: ajadhav@roosevelt.edu

Key words: cognitive bias, amygdala reactivity, HPA, resiliency, anxiogenesis

Received: April 29, 2015; Accepted: May 27, 2015; Published: May 29, 2015 


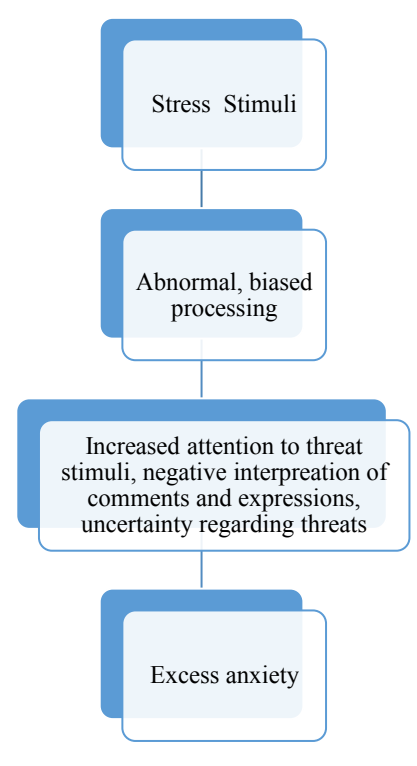

Figure 1. Overview of cognitive processing of stress stimuli in anxiety disorders (based on references cited in the text).

standing hypothesis that exposure to adverse environment during sensitive developmental phases is a risk factor for the development of mental disorders [30] has received considerable support by several studies carried out since then $[11,31,32]$. Briefly, these studies indicate that harsh environment generates stronger amygdala responses and individuals exposed to these environments are unable to recruit the prefrontal cortex effectively for regulating emotional responses to threatening cues [33]. Increased anxiety-related temperamental traits in young adults was found to be associated with increased amygdala and insula reactivity to certain types of emotional processing in social anxiety [34] and posttraumatic stress disorder (PTSD) [35].

Thus, amygdala reactivity to anxiogenic stimuli appears to be central in the pathogenesis of anxiety disorders and many studies indicate that it is affected by a variety of factors [36-42]. These studies indicate that 5-HTTLPR (serotonin-transporter-linked polymorphic region) may be a susceptibility factor for affective disorders by biasing the functional reactivity of the human amygdala when challenged with stress and/or deficient cortical regulatory input [38]. A functional variation in the human 5-HT1A gene [39,40], polymorphism in the androgen receptor gene [41], and regulatory variant of human tryptophan hydroxylase-2 gene [42] have also been observed to bias the reactivity of the amygdala. Recently role of sleep quality on the relationships between amygdala reactivity and perceived stress among men has also been examined [36].

\section{HPA and resiliency}

Similarly, investigations have also been focused on those mechanisms that may prevent or minimize the risk of triggering pathogenic changes leading to anxiety [43]. It has been proposed that processing of sensory data induce physiological changes (allostatic changes) that result in adaptive responses to maintain the homeostasis, and that the intensity and duration of these changes (allostatic overload or load) may trigger the onset of anxiogenic pathophysiology [44]. Using allostatic changes and allostatic load as a conceptual framework, efforts have been made to examine how the allostatic changes turn into allostatic load and what pharmacological manipulations may minimize the risk of allostatic changes becoming the allostatic load (resiliency). Role of hypothalamic-pituitary axis (HPA) in processing of stressinduced responses has been examined extensively, particularly as a potential targets for developing resiliency. The feedback mechanisms in the HPA regulate the intensity and duration of HPA activation in response to acute stress and are particularly important since they may contribute to the conversion of allostatic changes into allostatic load leading to psychopathology [43]. An overview of effects of reactivity and resilience on cognitive balance is shown in Figure 2.

\section{Animal models}

For research in animal models, a validity-based approach for testing role of various mechanisms that contribute to cognitive bias may be useful to spotlight the connectivity between cognitive bias and the underlying biology. The proposed criteria for validation of animal models for anxiety and depression studies [5] define a paradigm better suited for this type of focused research. By providing face validity, predictive validity, and construct validity, this paradigm has a potential to better connect the studies of cognitive bias with those focused on susceptibility or resilience. Development and use of endophenotypes for cognitive bias may also add to the progress made in this area. Anxiety endophenotypes such as impaired fear extinction and fear generalization for post-traumatic shock disorder [45], elevated startle response for general anxiety disorder [46], and increased blood oxygenation level dependent (BOLD) amygdala response to threat for panic disorders [47] offer opportunities to investigate the connectivity between cognitive bias and susceptibility of mechanisms mediated by amygdala and HPA further.

\section{Conclusion}

Thus, there is sufficient evidence in the literature to support role of cognitive processing of stressful stimuli in amygdala and generation of adaptive responses mediated by the HPA in anxiogenesis and susceptibility of these mechanisms to anxiogenic factors. A closer examination of these processes for their susceptibility to anxiogenic pathology may provide additional strategies for treatment of anxiety disorders.

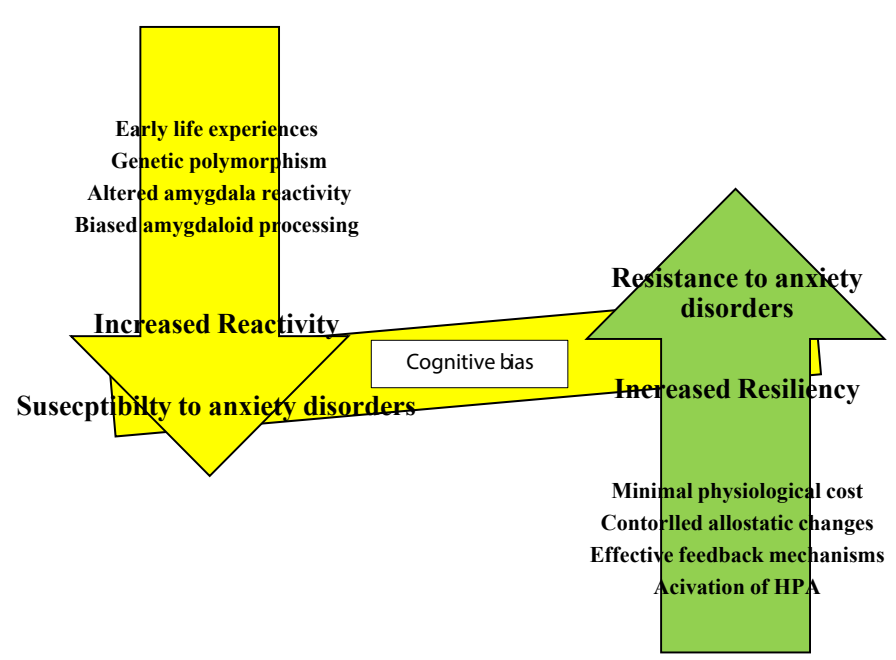

Figure 2. A conceptual overview of effects of reactivity (shown with the yellow arrow) and resilience (shown with the green arrow) on cognitive bias. 


\section{References}

1. Bishop SJ (2007) Neurocognitive mechanisms of anxiety: an integrative account, Trends Cogn. Sci. 11: 307-316. [Crossref]

2. Griebel G, Holmes A (2013) 50 years of hurdles and hope in anxiolytic drug discovery. Nat Rev Drug Discov 12: 667-687. [Crossref]

3. Baxter AJ, Scott KM, Vos T, Whiteford HA (2013) Global prevalence of anxiety disorders: a systematic review and meta-regression. Psychol Med 43: 897-910. [Crossref]

4. Baxter AJ, Vos T, Scott KM, Norman RE, Flaxman AD, et al. (2014) The regional distribution of anxiety disorders: implications for the Global Burden of Disease Study, 2010. Int J Methods Psychiatr Res 23: 422-438. [Crossref]

5. Belzung C, Lemoine M (2011) Criteria of validity for animal models of psychiatric disorders: focus on anxiety disorders and depression. Biol Mood Anxiety Disord 1: 9. [Crossref]

6. Russ VI (2012) "Mental Disorders”. In: Dan L. Longo, Anthony S. Fauci,, Dennis L. Kasper, Stephen L. Hauser, J. Larry Jameson, Joseph Loscalzo, Editors, Harrison's Principles of Internal Medicine, 18e, E-book on Access Pharmacy, McGraw-Hill, New York.

7. Kessler RC, Chiu WT, Demler O, Merikangas KR, Walters EE (2005) Prevalence, severity, and comorbidity of 12-month DSM-IV disorders in the National Comorbidity Survey Replication. Arch Gen Psychiatry 62: 617-627. [Crossref]

8. Bremner JD (2004) Brain imaging in anxiety disorders. Expert Rev Neurother 4: 275284. [Crossref]

9. Zald DH (2003) The human amygdala and the emotional evaluation of sensory stimuli. Brain Res Brain Res Rev 41: 88-123. [Crossref]

10. Kim MJ, Loucks RA, Palmer AL, Brown AC, Solomon KM, et al. (2011) The structural and functional connectivity of the amygdala: from normal emotion to pathological anxiety. Behav Brain Res 223: 403-410. [Crossref]

11. Braun K, Bock J, (2011) The experience-dependent maturation of prefronto-limbic circuits and the origin of developmental psychopathology: implications for the pathogenesis and therapy of behavioral disorders. Dev Med Child Neurol 53: 14-18. [Crossref]

12. Phelps EA, LeDoux JE (2005) Contributions of the amygdala to emotion processing: from animal models to human behavior. Neuron 48: 175-187. [Crossref]

13. Lang PJ, Davis M, Ohman A (2000) Fear and anxiety: animal models and human cognitive psychophysiology. J Affect Disord 61: 137-159. [Crossref]

14. Ehrlich I, Humeau Y, Grenier F, Ciocchi S, Herry C, et al. (2009) Amygdala inhibitory circuits and the control of fear memory. Neuron 62: 757-771. [Crossref]

15. Hirsch C, Mathews A (1997) Interpretative inferences when reading about emotional events. Behav Res Ther 35: 1123-1132. [Crossref]

16. Richards A, French CC, Calder AJ, Webb B, Fox R, et al. (2002) Anxiety-related bias in the classification of emotionally ambiguous facial expressions. Emotion 2: 273-287. [Crossref]

17. Cannistraro PA, Rauch SL (2003) Neural circuitry of anxiety: evidence from structural and functional neuroimaging studies. Psychopharmacol Bull 37: 8-25. [Crossref]

18. Castaneda AE, Tuulio-Henriksson A, Marttunen M, Suvisaari J, Lönnqvist J (2008) A review on cognitive impairments in depressive and anxiety disorders with a focus on young adults. $J$ Affect Disord 106: 1-27. [Crossref]

19. Sandi C, Richter-Levin G (2009) From high anxiety trait to depression: a neurocognitive hypothesis. Trends Neurosci 32: 312-320. [Crossref]

20. Heeren A, De Raedt R, Koster EH, Philippot P (2013) The (neuro)cognitive mechanisms behind attention bias modification in anxiety: proposals based on theoretical accounts of attentional bias. Front Hum Neurosci 7: 119. [Crossref]

21. MacLeod C, Rutherford E, Campbell L, Ebsworthy G, and Holker L (2002) Selective attention and emotional vulnerability: assessing the causal basis of their association through the experimental manipulation of attentional bias. J Abnorm Psychol 11: 107123. [Crossref]

22. Mathews A, MacLeod C (2005) Cognitive vulnerability to emotional disorders. Annu Rev Clin Psychol 1: 167-195. [Crossref]

23. Bar-Haim Y, Lamy D, Pergamin L, Bakermans-Kranenburg MJ, van IJzendoorn MH
(2007) Threat-related attentional bias in anxious and nonanxious individuals: a metaanalytic study. Psychol Bull 133: 1-24. [Crossref]

24. Beck AT (2008) The evolution of the cognitive model of depression and it neurobiological correlates. Am J Psychiatry 165: 969-977. [Crossref]

25. Cisler JM, Koster EH (2010) Mechanisms of attentional biases towards threat in anxiety disorders: An integrative review. Clin Psychol Rev 30: 203-216. [Crossref]

26. Rapee RM, Heimberg RG (1997) A cognitive-behavioral model of anxiety in social phobia. Behav Res and Ther 35: 741-756. [Crossref]

27. Clark DM (2001) A Cognitive Perspective on Social Phobia. International Handbook ofSocial Anxiety: Concepts, Research and Interventions Relating to the Self and Shyness. In: W. Ray Crozier and Lynn E (Eds.), Alden. John Wiley \& Sons Ltd.

28. Hofmann SG, Ellard KK, Siegle GJ (2012) Neurobiological correlates of cognition in fear and anxiety: a cognitive-neurobiological information-processing model. $\operatorname{Cog} n$ Emot 26: 282-299. [Crossref]

29. Berkowitz RL, Coplan JD, Reddy DP, Gorman JM (2007) The human dimension: how the prefrontal cortex modulates the subcortical fear response. Rev Neurosci 18: 191 207. [Crossref]

30. Spitz RA (1945) Hospitalism; an inquiry into the genesis of psychiatric conditions in early childhood. Psychoanal Study Child 1: 53-74. [Crossref]

31. Skeels HM (1966) Adult status of children with contrasting early life experiences. A follow-up study. Monogr Soc Res Child Dev 31: 1-56. [Crossref]

32. Suomi SJ, Eisele CD, Grady SA, Harlow HF (1975) Depressive behavior in adult monkeys following separation from family environment. J Abnorm Psychol 84: 576578. [Crossref]

33. Taylor SE (2010) Mechanisms linking early life stress to adult health outcomes. Proc Natl Acad Sci U S A 107: 8507-8512. [Crossref]

34. Birbaumer N, Grodd W, Diedrich O, Klose U, Erb M, et al. (1998) fMRI reveal amygdala activation to human faces in social phobics. Neuroreport 9: 1223-1226. [Crossref]

35. Rauch SL, Whalen PJ, Shin LM, McInerney SC, Macklin ML, et al. (2000) Exaggerated amygdala response to masked facial stimuli in posttraumatic stress disorder: a functional MRI study. Biol Psychiatry 47: 769-776. [Crossref]

36. Prather AA, Bogdan R, Hariri AR (2013) Impact of sleep quality on amygdala reactivity, negative affect, and perceived stress. Psychosom Med 75: 350-358. [Crossref]

37. Forster GL, Novick AM, Scholl JL, Watt MJ (2012) The Role of the Amygdala in Anxiety Disorders. InTech.

38. Hariri AR, Drabant EM, Munoz KE, Kolachana BS, Mattay VS, et al. (2005) A susceptibility gene for affective disorders and the response of the human amygdala. Arch Gen Psychiatry 62: 146-152. [Crossref]

39. Fakra E, Hyde LW, Gorka A, Fisher PM, Muñoz KE, et al. (2009) Effects of HTR1A C(-1019)G on amygdala reactivity and trait anxiety. Arch Gen Psychiatry 66: 33-40. [Crossref]

40. Kobiella A, Reimold M, Ulshöfer DE, Ikonomidou VN, Vollmert C, et al. (2011) How the serotonin transporter 5-HTTLPR polymorphism influences amygdala function the roles of in vivo serotonin transporter expression and amygdala structure. Transl Psychiatry. [Crossref]

41. Manuck SB, Marsland AL, Flory JD, Gorka A, Ferrell RE, et al. (2010) Salivary testosterone and a trinucleotide (CAG) length polymorphism in the androgen recepto gene predict amygdala reactivity in men.Psychoneuroendocrinology 35: 94-104. [Crossref]

42. Brown SM, Peet E, Manuck SB, Williamson DE, Dahl RE, et al. (2005) A regulatory variant of the human tryptophan hydroxylase-2 gene biases amygdala reactivity. $\mathrm{Mol}$ Psychiatry 10: 884-888, 805. [Crossref]

43. Feder A, Charney D, Collins K (2011) "Neurobiology of resilience". In: Resilience and Mental Health: Challenges across the life span. Ed. Southwick, S.M., Litz, B.T., Charney, D., and Friedman, M.J. Cambridge University Press.

44. McEwen BS (1998) Protective and damaging effects of stress mediators. $N$ Engl J Med 338: 171-179. [Crossref]

45. Steckler T, Risbrough V (2012) Pharmacological treatment of PTSD - established and new approaches. Neuropharmacology 62: 617-627. [Crossref] 
Jadhav AL (2015) Neural substrates of cognitive bias and anxiogenesis

46. Davis M, Walker DL, Miles L, Grillon C (2010) Phasic vs sustained fear in rats and humans: role of the extended amygdala in fear vs anxiety. Neuropsychopharmacology 35: 105-135. [Crossref]
47. Fisher PM, Hariri AR (2012) Linking variability in brain chemistry and circuit function through multimodal human neuroimaging. Genes Brain Behav 1: 633-642. [Crossref]

Copyright: (C2015 Jadhav AL. This is an open-access article distributed under the terms of the Creative Commons Attribution License, which permits unrestricted use, distribution, and reproduction in any medium, provided the original author and source are credited. 